\title{
Keanekaragaman Jenis Tanaman Obat di Kecamatan Peukan Baro Kabupaten Pidie
}

\author{
Zufahmi $^{1}$, Zuraida ${ }^{2}$ \\ Fakultas Keguruan dan Ilmu Pendidikan \\ Universitas Jabal Ghafur \\ zufahmibio@gmail.com
}

\begin{abstract}
Abstrak
Kecamatan Peukan Baro merupakan salah satu kecamatan yang terdapat di Kabupaten Pidie, Aceh. Kecamatan ini dinilai berpotensi memiliki keanekaragaman jenis tumbuhan obat. Penelitian ini bertujuan untuk mengetahui tingkat keanekaragaman jenis tanaman obat di Kecamatan Peukan Baro Kabupaten Pidie. Penelitian ini dilaksanakan di 14 desa yang berada di Kecamatan Peukan Baro. Teknik pengumpulan data dilakukan dengan wawancara, pengamatan langsung serta dokumentasi tanaman. Teknik analisis data menggunakan teknik kuantitatif yang selanjutnya dikaji menggunakan rumus Shannon-Wienner. Hasil Penelitian ditemukan 31 jenis tanaman obat yang terdiri dari 21 famili. Keanekaragaman jenis tanaman obat di Kecamatan Peukan Baro tergolong tinggi dengan nilai indeks 3,2169. Jenis tanaman obat terbanyak berasal dari famili Zingiberaceae. Bagian yang paling banyak digunakan sebagai obat adalah daun.
\end{abstract}

Kata Kunci: Keanekaragaman, Shannon- Wienner, Tanaman obat

\section{PENDAHULUAN}

Indonesia merupakan salah satu negara dengan tingkat keanekaragaman yang tinggi. Kekayaan alam Indonesia menyimpan berbagai tumbuhan yang berkhasiat obatdari 40 ribu jenis florayangtumbuh di dunia, 30 ribu diantaranya tumbuh diIndonesia. Sebanyak 26\%yangtelah dibudidayakan dan $74 \%$ masih tumbuh liardi hutan, dari 26\%yang telah dibudidayakan, sebanyak 940 jenis tanaman telah digunakan sebagai obat tradisional. Menurut World Health Organization (WHO), lebih dari 20.000 spesies tumbuhan berkhasiat obat digunakan olehpenduduk di seluruh dunia. Obat-obat tradisional umumnya menggunakan bahanbahan alamiah seperti akar, batang, daun, bunga dan buah (Sutardjo, 1999).

Tumbuhan obat merupakan tumbuhan yang penggunaan utamanya untuk keperluan obat-obatan tradisional. Pemanfaatan jenis tumbuhan obat merupakan salah satu kebiasaan masyarakat karena tumbuhan obat bersifat alami dari pada penggunaan obat modern. Sari(2006) menjelaskan bahwa penggunaan obat tradisional secara umum dinilai lebih aman dibandingkan dengan penggunaan obat modern. Hal ini disebabkan karena obat tradisional memiliki efek samping yang relatif lebih sedikit dari pada obat modern.

Santhyamidan Sulistyawati(2008) telah melakukan penelitian tentang Etno botani tumbuhan obat Oleh Masyarakat Adat Kampung Dukuh, Garut, Jawa Barat. Hasil penelitian menunjukan Penduduk kampung Dukuh mengklasifikasikan penyakit menjadi tiga jenis, yaitu penyakit biasa, penyakit karena magis dan penyakit karena makanan. Terdapat tiga bentuk pengobatan yang digunakan oleh penduduk untuk mengobati penyakit yaitu tatangkalan atau pengobatan dengan tumbuhan, obat warung, dan jampe. Kecamatan Peukan Baro Kabupaten Pidie merupakan salah satu daerah yang masih menjaga tradisi leluhur dengan memanfaatkan tanaman sebagai obat tradisional untuk mengobati suatu penyakit maupun mencegah penyakit. Selain menjaga tradisi, masyarakat Kecamatan Peukan Baro juga sangat menghargai sekaligus berguru pada alam sehingga mereka memiliki potensi pengetahuan yang besar tentang tumbuhan obat. Kondisi fisik lokasi ini mendukung berbagai tumbuhan dapat tumbuh dengan baik. Sebagian besar tumbuhan dimanfaatkan oleh masyarakat sebagai tanaman obat. Namun sampai saat ini belum ada data tentang tanaman obattradisionaldi Kecamatan Peukan Baro sertacara pemanfaatan tanaman obatoleh masyarakat. Penelitian ini bertujuan untuk mengetahui tingkat keanekaragaman jenis tanaman obat di Kecamatan Peukan Baro Kabupaten Pidie. Bagian tanaman yang digunakan sebagai obat tradisional meliputi akar, batang, daun, buah dan biji. Hasil 
penelitian ini dapat memberikan kontribusi positif bagi pengembangan ilmu pengetahuan, yaitu mengetahui potensi kekayaan alam dan menggali budaya masyarakat Kecamatan Peukan Baro dalam memanfaatkan tanaman obat serta usaha pelestariannya. Selain itu hasil penelitian ini juga berpotensi untuk menemukan jenis tanaman obat baru yang diharapkan dapat diteliti lebih lanjut oleh ahli farmasi dalam rangka peningkatan kesehatan masyarakat luas.

\section{METODE PENELITIAN}

\section{Tempat dan Waktu}

Penelitian ini dilakukandi Kecamatan Peukan Baro, Kabupaten Pidie. Lokasi penelitian meliputi seluruh kemukiman di Kecamatan Peukan Baro yang terdiri dari 14 Desa. Penelitian ini dilaksanakan pada bulan April-Juni 2017.

\section{Alat dan Bahan}

Alat yang digunakan pada penelitian ini adalah parang, meteran, kamera, gunting dan alat tulis menulis. Bahan yang digunakan adalah peta kawasan, tali rafia, Tally sheet, dan label gantung.

\section{Metode Penelitian}

Penelitian ini dilakukan dengan menggunakan metode petak ganda yang diletakkan secara sengaja (purposive sampling). Penentuan plot pengamatan diletakkan dimana ditemukan tumbuhan obat. Dalam tiap plot pengamatan, nama tumbuhan dan jumlah individu dicatat pada tabel pengamatan. Untuk memudahkan identifikasi, masing-masing tumbuhan didokumentasikan dengan menggunakan kamera.

\section{Analisis Data}

Indeks keanekaragaman jenis tanaman obat dianalisis dengan menggunakan indeks keanekaragaman Shannon-Wiener berdasarkan Odum (1998), yaitu :

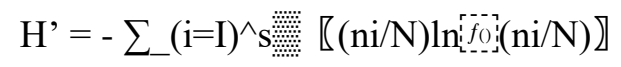

dimana:

$$
\begin{array}{ll}
\mathrm{s} & \text { : jumlah jenis } \\
\mathrm{ni} & \text { : jumlah individu jenis ke-i } \\
\mathrm{N} & \text { : jumlah individu semua jenis }
\end{array}
$$

Semakin benasr nilai $H^{\prime}$ menunjukan semakin tinggi keanekaragaman jenis. Besarnya nilai keanekaragaman jenis Shannon didefinisikan sebgai berikut :

$\mathrm{H}^{\prime}>3$ menunjukkan keanekaragaman jenis yang tinggi pada suatu kawasan.

$1 \leq \mathrm{H}^{\prime} \leq 3$ menunjukkan keaneragaman jenis yang sedang pada suatu kawasan.

$\mathrm{H}^{\prime}<1$ menunjukkan keanekaragaman jenis yang rendah pada suatu kawasan.

\section{Hasil Dan Pembahasan}

Berdasarkan hasil penelitian ditemukan 31 spesies tanaman obat diKecamatan Peukan Baro, Kabupaten Pidie yangterdiridari21 famili.

\begin{tabular}{|c|c|c|c|}
\hline No & NAMA LATIN & $\begin{array}{l}\text { NAMA } \\
\text { LOKAL }\end{array}$ & FAMIII \\
\hline 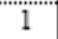 & Cweruma domestica & Kunyit & Zingiberaceae \\
\hline 2 & Zingiberofficinale & Jahe & Zingiberaceae \\
\hline 3 & Psiativnguqjava & JambuBiji & Myrtacese \\
\hline 4 & Annonamuricata & Sirsak & Annonaceae \\
\hline 5 & Hibiscus rosasinensis & kembangsepatu & Malvaceae \\
\hline 6 & Alos vera & lidahbuaya & Liliceae \\
\hline 7 & Carica papava & pepaya & Caricaceae \\
\hline 8 & Citrus aurantifolia & jeruknipis & Rutaceae \\
\hline 9 & Averrhoabilimbi & belimbing wuluh & Oxalidaceae \\
\hline 10 & Centellaasiatica & pegagan & Mackinlayaceae \\
\hline 11 & Piper botle & girih & Piperaceae \\
\hline 12 & Kampforiagalanga & kencur & Zingiberaceae \\
\hline 13 & Punicagranatum & delima & Lythaceae \\
\hline 14 & Sysygiwnpolyantum & daungalam & Myrtacese \\
\hline 15 & Lavsoniainermis & daunpacar & Lythraceae \\
\hline 16 & Apiumgraveolens & geledri & Apiaceae \\
\hline 17 & Tagetes erectus & dauntahiayam & Compositeae \\
\hline 18 & Alpinagalanga & lengkuas & Zingiberaceae \\
\hline 19 & Kalanchoepinnata & cocorbebek & Crassulaceae \\
\hline 20 & Cymbopogoncitratus & gereh & Poaceae \\
\hline 21 & Piper nigrum & lada & Piperaceae \\
\hline 22 & Cocosnucifera & kelapa & Arecaceae \\
\hline 23 & Areca catechu & pinang & Arecaceae \\
\hline 24 & Pandanusanaryllifolius & pandan & Pandanaceae \\
\hline 25 & Mumayahoenigii & daunkari & Rutaceae \\
\hline 26 & Phaleriamacrocarpa & mahkotadewa & Thymelacese \\
\hline 27 & Curcwna xanthorrhiza & temulawak & Zingiberaceae \\
\hline 28 & Citrus limon & lemon & Rutaceae \\
\hline 29 & Ficuscarica & buah tin & Moraceae \\
\hline 30 & Sauropusandrogynus & daunkatuk & Euphorbeaceae \\
\hline 31 & Morindacitrifolia & mengkudu & Rubiaceae \\
\hline
\end{tabular}
Hasil pengamatan dapat dilihat padaTabel 1 dibawah.

Tabel1. JenisTanaman Obat Di Kecamatan 
Famili tanaman obat terbanyak yang ditemukan adalah dari famili Zingiberaceae sebanyak 5 spesies, yaitu kunyit (Curcuma domestica), temulawak (Curcuma xanthorrhiza), jahe (Zingiber officinale), lengkuas (Alpinia galanga) dan kencur (Kampferia galanga). Famili Zingiberaceae merupakan kelompok tanaman yang spesiesnya paling banyak dibudidayakan oleh masyarakat, karena umumnya tanaman tersebut memiliki fungsi ganda yaitu dapat digunakan sebagai bumbu masak dan juga sebagai tanaman obat - obatan, sedangkan tanaman dari famili Rutaceae terdapat sebanyak 3 jenis dan famili lainnya berjumlah kurang dari 3 jenis.

Tanaman yang memiliki jumlah spesies terbanyak adalah tanaman sereh (Cymbopogon citratus) karena tanaman ini selain digunakan sebagai obat tradisional juga banyak digunakan sebagai rempah rempah dalam berbagai masakan. Sereh termasuk jenis tanaman yang dapat tumbuh dengan cepat (Sumiartha dkk, 2012). Kebanyakan masyarakat membudidayakan atau menanam tanaman ini di pekarangan rumahnya untuk dimanfaatkan ketika diperlukan. Selain itu tanaman ini juga sangat mudah berkembang biak dengan cepat. Adapun pemanfaatan tanaman obat dikecamatan Peukan Baro, Kabupaten Pidie disajikan pada Tabel 2.

Tabel 2. Pemanfaatan Tanaman Obat Di Kecamatan Peukan Baro, Kabupaten Pidie

\begin{tabular}{|c|c|c|c|c|c|}
\hline No & NAMA LATIN & $\begin{array}{l}\text { NAMA } \\
\text { LOKAL }\end{array}$ & FAMIII I & \begin{tabular}{|c|} 
BAGIAN \\
YANG \\
DIGUNAKAN
\end{tabular} & KHASIAT \\
\hline 1 & Cwrcuma domestica & Kunyit & Zingiberaceae & rimpang & menyembuhkan maag \\
\hline 2 & Zingiberofficioinale & Jahe & $\begin{array}{l}\text { Zingiberaceae } \\
\end{array}$ & rimpang & obat batuk \\
\hline 3 & Psidiumguajava & JambuBiji & \begin{tabular}{|l|} 
Myrtaceae \\
\end{tabular} & daun, buah & $\begin{array}{l}\text { obat diare, demam } \\
\text { berdarah }\end{array}$ \\
\hline 4 & Annonamuricata & $\begin{array}{l}\text { Sirsalk } \\
\text { nats }\end{array}$ & Annonaceae & daun & \begin{tabular}{|l|}
$\begin{array}{l}\text { diabetes, kanker } \\
\text { tumor }\end{array}$ \\
\end{tabular} \\
\hline 5 & Hibiscus rosasinensis & kembangsepatu & Malvaceae & daun & demam \\
\hline 6 & Aloe vera & lidahbuaya & \begin{tabular}{|l|} 
Liliceae \\
\end{tabular} & daun & luka bakar \\
\hline 7 & Carica papqua & pepaya & Caricaceae & daun & \begin{tabular}{|l|l|} 
demam \\
diabetes
\end{tabular} berdarah, \\
\hline 8 & Citrus aurantifolia & jeruknipis & Rutacease & buah & obat batuk \\
\hline 9 & Averhoabilimbi & belimbingwuluh & Oxalidaceae & dawn, buah & obat batuk, sariawan \\
\hline 10 & Centellaasiatica & pegagan & Mackinlayaceae & daun & \begin{tabular}{|l|} 
hipertensi \\
\end{tabular} \\
\hline 11 & \begin{tabular}{|l} 
Piper betle \\
\end{tabular} & sirh & \begin{tabular}{|l} 
Piperaceae \\
\end{tabular} & daun & $\begin{array}{l}\begin{array}{l}\text { mimigan, encerkan } \\
\text { dahak }\end{array} \\
\end{array}$ \\
\hline 12 & Kampferiagalanga & kencur & \begin{tabular}{|l} 
Zingiberaceae \\
\end{tabular} & rimpang & \begin{tabular}{|l|} 
diare, obat memar \\
\end{tabular} \\
\hline 13 & Punicagranatum & delima & \begin{tabular}{|l|} 
Lythacease \\
\end{tabular} & biji & \begin{tabular}{|l|} 
sariawan \\
\end{tabular} \\
\hline 14 & Siaveiumpolvantum & daunsalam & \begin{tabular}{|l|} 
Myrtaceae \\
\end{tabular} & daun & \begin{tabular}{|l|} 
kolesterol \\
\end{tabular} \\
\hline 15 & Lawsoniainermis & daunpacar & Lythracease & daun & menyembuhkan luka \\
\hline 16 & \begin{tabular}{|l} 
Apiumgraveolens \\
\end{tabular} & seledri & Apiaceae & daun, batang & rematik, anemia \\
\hline 17 & Tagetes erectus & dauntahiayam & Compositeae & daun & \begin{tabular}{|l|} 
sakit perut \\
\end{tabular} \\
\hline 18 & Alpinagalanga & lengkuas & Zingiberacease & rimpang & 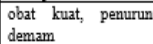 \\
\hline 19 & Kalanchoepinnata & cocorbebek & \begin{tabular}{|l} 
Crassulaceae \\
\end{tabular} & daun & \begin{tabular}{|l|l|l|l|l|l} 
nyeri lambung, \\
penurun demam
\end{tabular} \\
\hline 20 & Cymbopogoncitratus & Sereh & \begin{tabular}{|l|l|} 
Poaceae \\
\end{tabular} & batang & \begin{tabular}{|l} 
kolesterol \\
\end{tabular} \\
\hline 21 & Piper nigrum & lada & Piperaceae & biji & sakit kepala / flu \\
\hline 22 & Cocosnucifera & kelapa & Arecaceae & buah & menyembuhkan alergi \\
\hline 23 & Areca catechu & pinang & Arecaceae & biji & $\begin{array}{l}\begin{array}{l}\text { kesehatan gigi dan } \\
\text { gusi }\end{array} \\
\end{array}$ \\
\hline 24 & Pandanusamaryllifolius & pandan & Pandanaceae & dawn & \begin{tabular}{|l|} 
kolesterol \\
\end{tabular} \\
\hline 25 & Murravakoenigii & daunkari & Rutaceas & daun & kolesterol \\
\hline 26 & Phaleriamacrocarpa & mahkotadewa & Thymelaceae & buah & \begin{tabular}{|l|} 
diabetes \\
\end{tabular} \\
\hline 27 & Curcuma xanthorrhiza & \begin{tabular}{|l|} 
temulawak \\
\end{tabular} & Zingiberaceae & umbi & \begin{tabular}{|l|} 
kolesterol \\
\end{tabular} \\
\hline 28 & \begin{tabular}{|l|} 
Citrus limon \\
\end{tabular} & lemon & Rutaceae & buah & $\begin{array}{l}\text { sakit tenggorokan, } \\
\text { mengurangi ketombe }\end{array}$ \\
\hline 29 & Ficuscarica & buah tin & Moraceae & daun, buah & \begin{tabular}{|l|l|}
$\begin{array}{l}\text { kanker, } \\
\text { anemia }\end{array}$ & kolesterol, \\
\end{tabular} \\
\hline 30 & Sauropusandrogynus & \begin{tabular}{|l|l} 
daunkatuk \\
\end{tabular} & Euphorbeaceae & daun & \begin{tabular}{|l|} 
melancarkan asi \\
\end{tabular} \\
\hline 31 & $\begin{array}{l}\text { Morindacitrifolia } \\
\end{array}$ & mengkudu & Rubiacease & daun, buah & kolesterol, hipertensi \\
\hline
\end{tabular}

Pemanfaatan tanaman obat oleh masyarakat di setiap desa di Kecamatan Peukan Baro meneunjukkan kesamaan, hal ini disebabkan karena pengetahuan tentang pemanfaatan tanaman obat diperoleh secara turun temurun dari leluhur. Oleh karena itu penggunaan tanaman obat di wilayah ini masih tergolong banyak, namun kebanyakan hanya kaum ibu ibu atau orang tua yang masih memanfaatkan tanaman obat dan mengetahui cara pemanfaatannya. Kaum muda mudi beralih menggunakan cara modern dengan alasan lebih praktis.

Nilai indeks keanekaragaman jenis tanaman obat di Kecamatan Peukan Baro dapat diketahui dengan menggunakan rumus indeks keanekaragaman Shannon - Wienner diperoleh 3,2169. Hasil perhitungan indeks keanekaragaman jenis tanaman obat di Kecamatan Peukan Baro Kabupaten Pidie menunjukkan bahwa keanekaragaman jenisnya tinggi. Hal ini dikarenakan beberapa faktor, diantaranya masyarakat di Kecamatan Peukan Baro masih menggunakan tanaman obat untuk penyembuhan berbagai penyakit, sehingga banyak diantara mereka yang membudidayakan tanaman obat di pekarangan rumahnya masing masing untuk dimanfaatkan langsung ketika diperlukan. Bahkan ada masyarakat yang sengaja memanfaatkan lahan pekarangan rumahnya untuk ditanami berbagai tanaman obat untuk kemudian diolah menjadi jamu tradisional untuk dijual. Hal inilah yang semakin memperkaya keanekaragaman tanaman obat di Kecamatan Peukan Baro.

Selain itu, kondisi wilayah juga sangat menentukan terhadap keanekaragaman jenis tanaman di wilayah tersebut. Kecamatan Peukan Baro diketahui memiliki iklim dan curah hujan yang cukup baik untuk menunjang perkembangbiakan tanaman. Wilayah ini juga masih asri dengan banyaknya lahan hijau yang bisa dimanfaatkan masyarakat untuk bercocok tanam (Suciantini, 2015).

\section{SIMPULAN DAN SARAN}

Keanekaragaman tanaman obat di Kecamatan Peukan Baro Kabupaten Pidie tergolong tinggi dengan nilai indeks keanekaragaman 3,2169. Umumnya tanaman obat digunakan dalam bentuk bahan tunggal, dikonsumsi langsung, direbus atau ditempelkan untuk penggunaan luar. Budidaya tanaman obat tradisional perlu dibudidayakan oleh masyarakat dengan memanfaatkan pekarangan rumah 
sehingga dapat memberikan manfaat terhadap dirinya, keluarga dan masyarakat di daerah tersebut. Upaya konservasi dan pelestarian tanaman obat perlu terus ditingkatkan dengan cara menciptakan hubungan kerjasama yang sinergis antara lembaga - lembaga konservasi dengan masyarakat.

\section{DAFTAR PUSTAKA}

Abdiyani, S. (2008). Keanekaragaman Jenis Tumbuhan Bawah Berkhasiat Obat di Dataran Tinggi Dieng. Jurnal Penelitian Hutan dan Konservasi Alam. 5:1,79-92.

Allo, M. K.(2010).KajianKeragaman Tumbuhan Hutan Berkhasiat Obat Berdasarkan Etno botani dan Fitokimia diTaman NasionalLoreLindu. Laporan Hasil Penelitian Insentif TA.2010Flora Faunadan Mikro organisme.Balai Penelitian Kehutanan Makassar.

Depkes, R.I. (2007).Keputusan MenteriKesehatan Republik Indonesia No381/MENKES/SK/III/200 tentang Kebijakan ObatTradisional Nasional.

Fachrul,M.F. (2007) Metode Sampling Bioekologi. Bumi Aksar a: Jakarta.

Hamzari. (2008). Identifikasi Tanaman ObatObatan Yang Dimanfaatkan Oleh Masyarakat Sekitar Hutan TaboTabo.Jurnal Hutan Dan Masyarakat. 3:2,111-234.

Rahayu,M. (2005). Pengetahuan dan Pemanfaatan Tumbuhan Obat Oleh Masyarakat kaili Sekitar Taman Nasional Lore Lind, Sulawesi Tengah. Jurnal Bahan Alam Indonesia. 4:1,1412-2855

Rifai,M.A. (1998). Pemasakinian Etnobotani Indonesia : Suatu Keharusan demi Peningkatan Upaya Pemanfaatan, Pengembangan dan Penguasaannya. Prosiding Seminar Nasional EtnobotaniIII(5-6 Mei 1998, DenpasarBali) : 352-356.

Santhyami dan Endah Sulistyawati. (2008).Etnobotani Tumbuhan Obat oleh Masyarakat Adat Kampung Dukuh, Garut, Jawa Barat.Schoolof Life Science\&Technolog. Bandung Institute of Technology: Indonesia.

Sari,Kumala dan R,O, Lusia.(2006). Pemanfaatan Obat Tradisional Dengan Pertimbangan Manfaat dan Keamanannya. Majalah Ilmu Kefarmasian.I:3, 1-7.
Sari,N.I.(2010).Studi

Etnobotani

TumbuhanHerba Oleh Masyarkat Karo diKawasan Taman Nasional Gunung Leuser. (Studi Kasus di Desa Telagah Kecamatan Sei Bingai Kabupaten Langkat). Skripsi. Departemen Biologi Fakultas Matematika Dan Ilmu Pengetahuan Alam Universitas Sumatra UtaraMedan.

Siagian,M.H\&Sunaryo.(1996). Pemanfaatan Suku Zingiberaceae Sebagai Obat Tradisional oleh Masyarakat Lembak Delapan, Bengkulu, Abstr. 0554. Hlm 246 Dalam Indeks Beranotasi Keanekaragaman Hayati dalam Publikasi Ilmiah Staf Peneliti Pusat Penelitian Biologi-LIPI,2002.Biodiversity

ConservationProject, Pusat Penelitian Biologi-LIPI,Bogor.

Siswanto. (1997). Sayuran Dataran Tinggi. Penebar Swadaya: Jakarta.

Sumiartha, Ketut. Kohdrata, Naniek \& S. Antara, Nyoman. (2012). Budidaya dan Pasca Panen Tanaman Sereh (Cymbopogon citratus). Modul Pelatihan. Universitas Udayana.

Susciasti, R. (2004). Perencanaan Program Konservasi Tumbuhan Obat DiTaman Hutan Kampus Leuwikopo Kampus IPB Darmaga.Karya Ilmiah. Departemen Konservasi Sumberdaya Hutan Fakultas Kehutanan InstitutPertanian Bogor.

Sutardjo, R, M, Edhi. (1999).Pengobatan Tradisional. Anekallmu: Semarang.

Windadri, F.H., M. Rahayu,T.Uji\&H. Rustiami. (2006). Pemanfaatan Tumbuhan Sebagai Bahan ObatOleh Masyarakat LokalSuku Munadi Kecamatan Wakarumba, Kabupaten Muna,Sulawesi Utara.Biodiversitas7:4,333-339.

Zein, U. (2005). Pemanfaatan Tumbuhan Obat Dalam Upaya Pemeliharaan Kesehatan. Devisi Penyakit Tropik Dan Infeksi Bagian Ilmuh Penyakit Dalam Fakultas Kedokteran UniversitasSumatra Utara.

Zuhud, E.A.M.,B. Sambas,S.Rinekso, Ekarelawan dan S. Erna. (1994). Perkembangan dan Program Penelitian Tumbuhan Obat di Indonesia.Pro- siding Seminar Pelestarian Pemanfaatan Keanekaragaman Tumbuhan Obat Hutan Tropika Indonesia. Fa- hutan IPB dan LATIN. Bogor. 